\title{
ESTADO DE MALESTAR (MALESTAR EXHUBERANCIA ANOMALÍA): EL ENSAYO VISUAL COMO CATALIZADOR DE EXPERIENCIAS COMPARTIDAS
}

\author{
Laia Manonelles Moner ${ }^{1}$ \\ Universidad de Barcelona
}

\begin{abstract}
María Ruido, en su ensayo visual Estado de Malestar (malestar_exhuberancia_anomalía) (2018), recoge el pensamiento de pensadores, activistas y personas diagnosticadas, para reflexionar sobre la sintomatología social y las denominadas "enfermedades del vacío" (depresión, insomnio, ansiedad) vinculadas al "realismo capitalista". La artista da la palabra a los filósofos Mark Fisher, Franco Berardi y Santiago López Petit, al psiquiatra Guillermo Rendueles, al curador Alfredo Aracil y a representantes del colectivo InsPiradas de Madrid para articular un relato audiovisual en el que se expone la dimensión colectiva, sistémica, del malestar. En el presente artículo se ahondará en los diálogos generados en el video ensayo y se examinará la potencialidad de la creación para pensar otras maneras de abordar, transformar y politizar el malestar social.
\end{abstract}

Palabras clave: María Ruido; realismo capitalista; video ensayo; malestar social.

\section{STATE OF DISTRESS (DISTRESS_EXUBERANCE_ANOMALY): THE VISUAL ESSAY AS A CATALYST OF SHARED EXPERIENCES}

María Ruido, in her visual essay State of Distress (distress_exuberance anomaly) (2018), gathers the thoughts of thinkers, activists and people diagnosed, to reflect on the social symptomatology and the so-called "diseases of the vacuum" (depression, insomnia, anxiety) linked to "capitalist realism". The artist gives the word to philosophers such as Mark Fisher, Franco Berardi and Santiago López Petit, the psychiatrist Guillermo Rendueles, the curator Alfredo Aracil and representatives of the collective InsPiradas to articulate an audiovisual story in which the collective and systemic dimension of the malaise is exposed. In this article we will delve into the dialogues generated in the video essay and examine the potential of creation to think about other ways to approach, transform and politicize the social malaise.

Key words: María Ruido; capitalist realism; video essay; social malaise.

Cómo citar este artículo / Citation: Manonelles Moner, Laia (2020): "Estado de malestar (malestar exhuberancia_anomalía): el ensayo visual como catalizador de experiencias compartidas". En: Archivo Español de Arte, vol. 93, núm. 369, Madrid, pp. 39-54. https://doi.org/10.3989/aearte.2020.03.

\section{Introducción}

Somos locas y orgullosas, estamos aquí para visibilizar nuestra doble presión como mujeres y locas y nuestra doble lucha, contra el sistema psiquiátrico y el sistema cis-heteropatriarcal, estamos para denunciar estos sistemas. Que cuando presentamos señales de maltrato, abusos y violaciones se conforman con darnos un diagnóstico, con convertiros en trastornadas mentales, con empastillarnos y aislarnos, haciéndonos creer que el problema es nuestro, que estamos enfermas. Denunciamos la sobremedicación de las mujeres, para silenciarnos y mantener intactas las

\footnotetext{
1 laiamanonelles@ub.edu / ORCID iD: http://orcid.org/0000-0003-0738-0811.
} 
estructuras que sustentan nuestra opresión. Denunciamos las expectativas misóginas y machistas en nuestros procesos de sanación, así como la feminización de los síntomas².

El colectivo feminista InsPiradas, formado por mujeres activistas en salud mental, leyó un manifiesto - en el marco del día del Orgullo Loco en Madrid ${ }^{3}$ - con la determinación de tomar la palabra y denunciar un malestar sistémico que es tratado como algo individual, descontextualizado de un escenario de precariedad laboral, recortes sociales y desigualdades de género. María Ruido, en su ensayo visual Estado de Malestar (malestar exhuberancia anomalía) (2018), recoge el discurso pronunciado en dicha manifestación y reflexiona sobre la sintomatología social y el sufrimiento provocado por el sistema de vida impulsado por el realismo capitalista ${ }^{4}$.

En el inicio del vídeo ensayo María Ruido revela, mientras enfoca unos reflejos de luz en la superficie del mar, que empezó a rumiar este trabajo después de un episodio de quiebra que la llevó a ir a terapia y a que le prescribieran antidepresivos. La artista explica cómo, desde aquel momento, comenzó a pensar que aquello nos puede suceder a todos en algún momento de nuestras vidas: "me interesa explorar esa fragilidad que todos y todas tenemos, el yo neoliberal nos convierte en personas en extremo frágiles y, por otra parte, tiene una potencia política muy fuerte toda esa fragilidad". Estas afirmaciones de María Ruido son esenciales, a modo de prefacio de lo que seguirá, puesto que la autora se posiciona desde la primera persona del singular y conecta de manera directa la experiencia individual con la colectiva. Los relatos que se entretejen cuestionan al poder terapéutico como un instrumento de control normativo al mismo tiempo que exploran, desde diversas experiencias, otras maneras de abordar el malestar social, retornándolo a una dimensión política.

Estas reflexiones se complementan —en distintos momentos del ensayo visual - con otras narraciones, siendo especialmente significativo un fragmento de un texto del Colectivo Socialista de Pacientes (SPK), leído por un niño, que conecta directamente con las demandas del colectivo feminista InsPiradas. "Convertir la enfermedad en un arma" $(1972)^{5}$ advertía que estar sano significa poder ser explotado, producir y reproducirse, en el marco de un sistema capitalista en el que la enfermedad es el resultado de las condiciones de vida de dicho sistema productor. Max, el niño que lee el texto, ofrece su voz para recalcar que es preciso convertir el dolor privado en ira politizada y, en la misma dirección, una niña lee una cita sobre el descontento frente a la felicidad obligatoria del realismo capitalista: "La depresión colectiva es el resultado del enorme proyecto de re-subordinación de la clase dirigente, junto al estado de paralización inducida, la propagación del voluntarismo mágico fue un factor crucial para el éxito del neoliberalismo y la privatización del estrés, su campo de batalla ideológico". A tales reflexiones le siguen unas simbólicas imágenes de ocio en la playa en verano.

Griselda Pollock expone que los procesos creativos pueden ser "ejemplares" en relación a la posibilidad de generar símbolos que faciliten la liberación del significado, abriendo caminos hacia transformaciones ${ }^{6}$. La creación puede vincularse estrechamente con el activismo y la política, enfocando desde distintos prismas las injusticias que la sociedad neoliberal ejerce sobre la

\footnotetext{
${ }^{2}$ Fragmento extraído del video ensayo Estado de Malestar (malestar exhuberancia anomalía) (2018) de María Ruido, expuesto en el Centro Arts Santa Mónica, Barcelona, del 13 de noviembre de 2018 al 13 de enero de 2019. Estado de Malestar (malestar_exhuberancia_anomalia) está producido por la Xarxa de Centres d'Arts Visuals de Cataluña, Arts Santa Mònica-Departament de Cultura y LOOP Barcelona.

${ }^{3}$ El día del Orgullo Loco, celebrado el 20 de mayo del 2018 en distintas capitales españolas bajo el lema "El Orgullo Lo Cura", fue organizado por un grupo de personas de distintas asociaciones de salud mental, grupos de apoyo mutuo y colectivos activistas para combatir los estigmas y la discriminación hacia las personas con problemas de salud mental, reivindicando un papel activo en la toma de decisiones médicas, sociales y políticas. En: $<$ https://consaludmental.org/eventos/dia-orgullo-loco-35688/> [5 de enero de 2019].

${ }_{4}$ El pensador Mark Fisher desarrolla tal concepto, haciendo un guiño al "realismo socialista", en su publicación Realismo capitalista ¿No hay alternativa? (2017).

5 Colectivo Socialista de Pacientes, 1972: 199-203.

${ }^{6}$ Griselda Pollock impartió, en el Centro de Documentación y Estudios Avanzados de Arte Contemporáneo (CENDEAC) de Murcia, el curso Trauma y memoria cultural: cultura y catástrofe en el siglo XX (2004).
} 
ciudadanía ${ }^{7}$. En un contexto de crisis individual y social, enmarcada en un escenario de desigualdades y precariedad; ¿puede la creación devenir un medio para crear otros modos de hacer que transformen y politicen el malestar? ¿Pueden las prácticas creativas trascender el ámbito meramente artístico e impulsar un pensamiento crítico? ¿Desde dónde se produce este pensamiento y estas acciones críticas? A partir del vídeo ensayo Estado de Malestar (malestar_exhuberancia_ anomalía) se examinará la potencialidad de la creación para politizar el sufrimiento, investigando si las prácticas artísticas pueden abrir espacios de encuentro, de diálogo y de cambio.

\section{Estado de Malestar (malestar_exhuberancia_anomalía)}

María Ruido en su obra Estado de Malestar parte de una zozobra personal y la contextualiza para relacionarla con un malestar sistémico y con las denominadas enfermedades del vacío (depresión, insomnio, ansiedad) del realismo capitalista. La artista toma la palabra y da la palabra a pensadores, colectivos y personas directamente afectadas y diagnosticadas por dichas patologías, reflexionando sobre la fragilidad y la potencialidad política de una fuerza vulnerable . $^{8}$

A estas distintas voces, en el inicio del vídeo ensayo, se le suma la narración de una periodista que nos sitúa el contexto sociopolítico que enmarca los distintos relatos. Dicha voz extraída de los informativos, acompañada por imágenes de flores que podrían evocar una ofrenda u homenaje, anuncia una trágica noticia: "nuevo suicidio entre los trabadores de France telecom. Un operador de 57 años y padre de 4 hijos se inmoló con fuego en las inmediaciones de las oficinas de la empresa en Burdeos, los sindicatos denuncian las condiciones laborales de los trabajadores y hacen responsable a la compañía de varias decenas de suicidios en los últimos años". A esta crónica le sigue la voz en off del psiquiatra Guillermo Rendueles que recuerda cómo el sistema capitalista pauta que el sujeto devenga gestor de sí mismo ${ }^{9}$, adquiriendo lo que se denomina "capital social", estando el trabajador siempre disponible, en estado de alerta, como en tiempos de guerra. Rendueles revela que su última publicación trata sobre el suicidio y, en uno de los capítulos, se centra especialmente en el suicidio por causas políticas y laborales, mencionando el caso de determinados trabajadores especializados como los soldadores que - con el proceso de modernización - pierden su trabajo y estatus social ${ }^{10}$. Rendueles también expone la situación de explotación y malestar de las trabajadoras de fábricas textiles de Asturias que mejoraron sustancialmente cuando trascendieron el relato individual — en relación a su sufrimientoy lo articularon encuadrándolo con los abusos laborales vividos. Rendueles apunta que sugería a sus pacientes que se dirigiesen a un comité de empresa en lugar de acudir al psiquiatra ${ }^{11}$. Dicho de otro modo; las alentaba a traspasar la angustia individual a una esfera social, para así politizar el malestar y compartirlo.

Rendueles denuncia la psiquiatrización de la vida cotidiana y apunta una perspectiva de género, presente en todo el vídeo ensayo, que será esbozada por distintas voces y por dicho autor cuando señala, en otro fragmento de la conversación, que hay un mayor número de mujeres usuarias de salud mental. Tales observaciones van acompañadas por imágenes de archivo que muestran una mujer que conduce a sus dos perros en un concurso canino [fig. 1], jóvenes en una ceremonia de graduación, anuncios publicitarios que ofrecen estereotipados clichés femeninos, y también imágenes de voladuras en canteras y fábricas con sus trabajadores y trabajadoras. El psiquiatra recalca que los datos previamente mencionados son atribuidos a la genética, a las

\footnotetext{
7 Manonelles Moner, 2017.

8 Amador Fernández-Savater reflexiona sobre la potencialidad de la vulnerabilidad en varios de sus textos. Véase Fernández-Savater, 2017: 35-55.

9 Martí Peran, en la exposición y ensayo Indisposició general. Assaig sobre la fatiga, ahonda en la ideología "Do it" y su alianza con el capital. Peran, 2015: 20-43.

${ }^{10}$ Rendueles, 2018. Hay que apuntar que Guillermo Rendueles es psiquiatra y ensayista, además de trabajar directamente con los pacientes de un centro del Insalud en Asturias desde los años ochenta.

11 Rendueles, 2005: 33-46.
} 


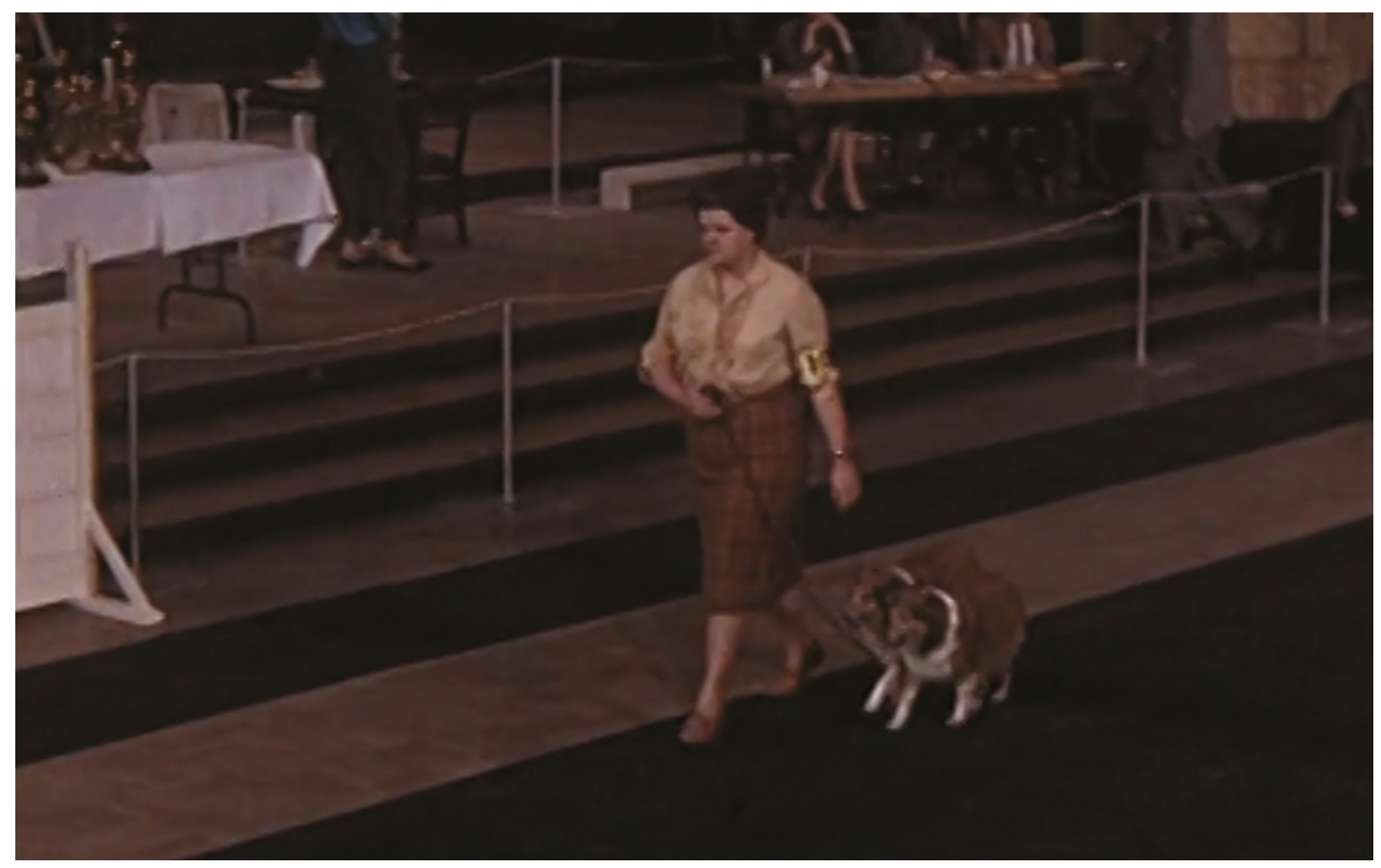

Fig. 1. María Ruido. Estado de Malestar (malestar_exhuberancia_anomalía). 2018. Secuencia del vídeo ensayo. Imagen cortesía de la artista.

hormonas y a la hipersensibilidad femenina, en lugar de vincularlos con la situación de opresión que muchas mujeres viven, a su papel de mediadoras y agentes sociales de la familia y a su labor en el cuidado de personas dependientes, sean ancianos, enfermos o niños ${ }^{12}$. Rendueles, desde su propia experiencia laboral, subraya que las demandas de salud mental tienen que ver con las patologías de la vida cotidiana en un contexto de explotación y desigualdades sociales y de género. Estas ideas quedan contrapuestas con escenas de ocio en la playa, del archivo de la familia Bensai ${ }^{13}$, y con las secuencias de una madre con sus dos hijos paseando por la ciudad. Asimismo, Rendueles expone cómo gran parte de las consultas de salud mental solicitan medicación para atenuar los sufrimientos, para "soportarlos" sin cambiar las relaciones laborales o de pareja ${ }^{14}$, puesto que los antidepresivos tienen un efecto distanciador de la situación que Rendueles relaciona con el "opio del pueblo"15. Estas reflexiones quedan reforzadas por varios fragmentos, extraídos del corto Ombres chinoises (1982) de Raoul Ruiz, que evocan la violencia de las relaciones, los fantasmas y los miedos.

12 Manonelles Moner, 2018: 165-177. Manonelles Moner, 2016: 253-272.

13 Las películas domésticas de Monsieur Bensai, nacido en Casablanca, fueron adquiridas por María Ruido en la medina de Tánger y vertebran su obra L'oeil impératif (El ojo imperativo, 2015) enfocando la mirada autoetnográfica con la que Bensai retrata su país. (Del Diego, 2015: 8).

${ }^{14}$ Franco Berardi "Bifo" reflexiona sobre el nacimiento de la biopolítica y señala cómo, en los años noventa, explota una nueva moda farmacológica con productos que no tienen un efecto hipnótico y relajante sino euforizante: "A mitad de los '90, la década que dio el máximo impulso a la economía cognitiva y que requería de una movilización total de las energías mentales del trabajo creativo, nació el Prozac, una verdadera mitología [...]. Las decisiones económicas de la clase global son un reflejo fiel de las sustancias que le permitieron a quienes tomaban las decisiones ver sólo el aspecto eufórico del mundo e ignorar perversamente los efectos de devastación determinados por la euforia económica". Berardi, 2007: 186.

15 Rendueles también apunta sobre dichos temas: "Los nuevos tipos de enfermedad, eso que llaman burn-out (queme en el trabajo), la fibromialgia, la distimia........ En las consultas médicas se inician escaladas que no logran curar esas seudoenfermedades y se recetan cataratas de fármacos que cronifican la malaria urbana". Rendueles, 2001: 1. 


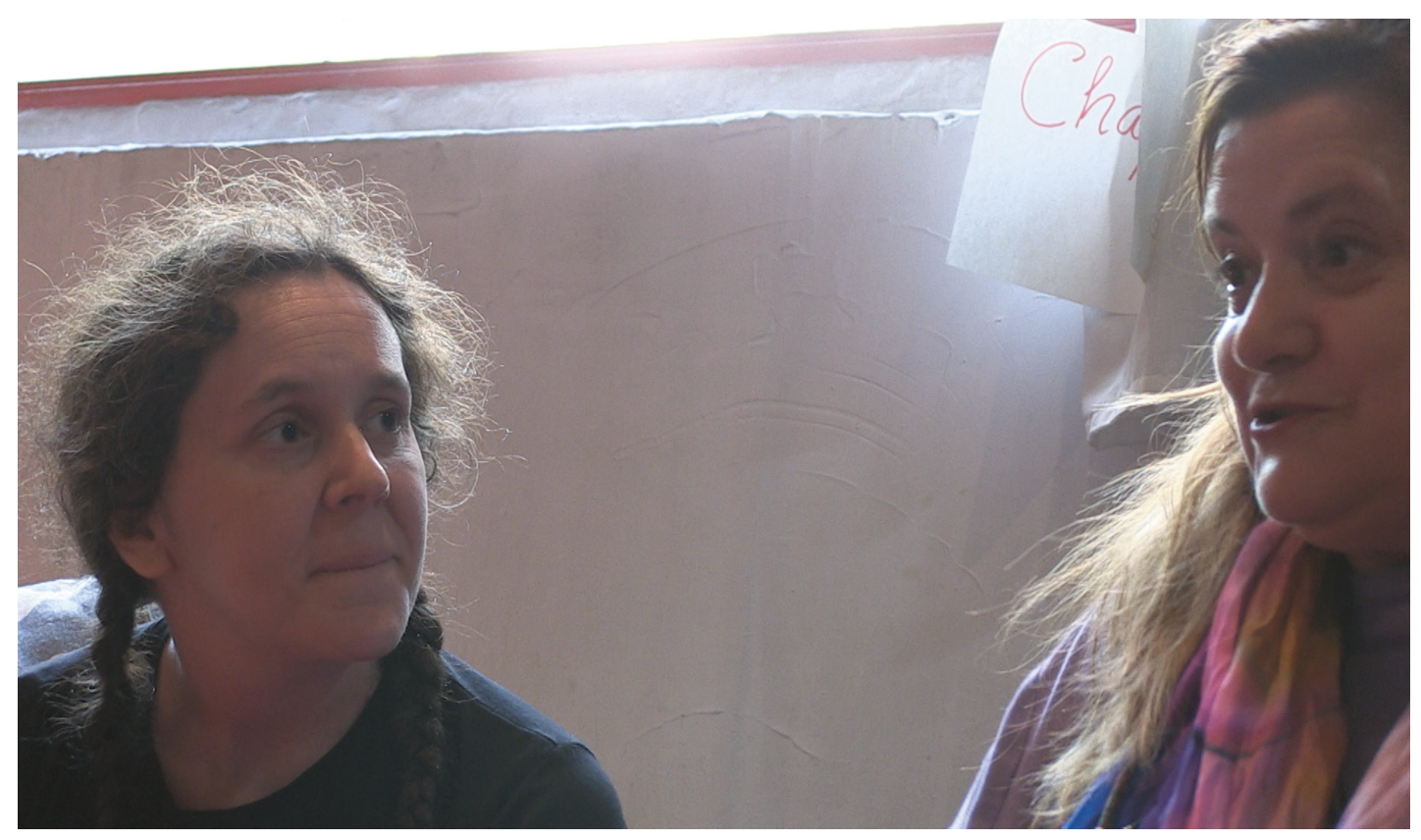

Fig. 2. María Ruido. Estado de Malestar (malestar_exhuberancia_anomalía). 2018. Secuencia del vídeo ensayo. Imagen cortesía de la artista.

A partir de los testimonios esbozados, de la experiencia clínica de Guillermo Rendueles y del colectivo de mujeres InsPiradas, es pertinente retomar la premisa de Carol Hanish de que lo personal es político (the personal is political), especialmente cuando dicha autora confronta la "terapia individual" a la "terapia política".

So the reason I participate in these meetings is not to solve any personal problem. One of the first things we discover in these groups is that personal problems are political problems. There are no personal solutions at this time. There is only collective action for a collective solution. [...] This is not to deny that these sessions have at least two aspects that are therapeutic. I prefer to call even this aspect «political therapy» as opposed to personal therapy ${ }^{16}$.

Carol Hanish revela que, para construir dicho texto, fueron fundamentales los encuentros y diálogos con los grupos de conciencia política (consciousness-raising) en los que se pensaban colectivamente problemas considerados "personales" —en relación al trabajo, a la pareja, a la sexualidad, al aborto y el cuidado de los hijos e hijas - para devolverlos a unas coordenadas sociales y políticas en un sistema claramente patriarcal que separaba el espacio público y productivo, vinculado tradicionalmente con el género masculino, y un espacio doméstico y reproductivo relacionado con el género femenino. Carol Hanisch colaboró con las plataformas feministas Women's liberation movement y New York radical women desde las que pensaban acciones comunitarias para afrontar problemáticas colectivas, siendo esencial en este proceso de politización de la existencia la participación en grupos de autoconciencia o de concienciación política. Hay que remarcar que dicha autora se preocupa por enfocar la potencialidad terapéutica de estas reuniones, utilizando el término

16 "La razón por la que participo en estas reuniones no es para resolver ningún problema personal. Una de las primeras cosas que descubrimos en estos grupos es que los problemas personales son problemas políticos. No hay soluciones personales en este momento. Sólo hay acción colectiva para una solución colectiva. [...] No niego que estas sesiones tengan al menos dos aspectos terapéuticos. Prefiero llamar a este aspecto «terapia política» en lugar de terapia personal". Traducción de la autora. Hanish, 1969. En: <http://www.carolhanisch.org/CHwritings/PIP.html> [6 de abril de 2018]. 


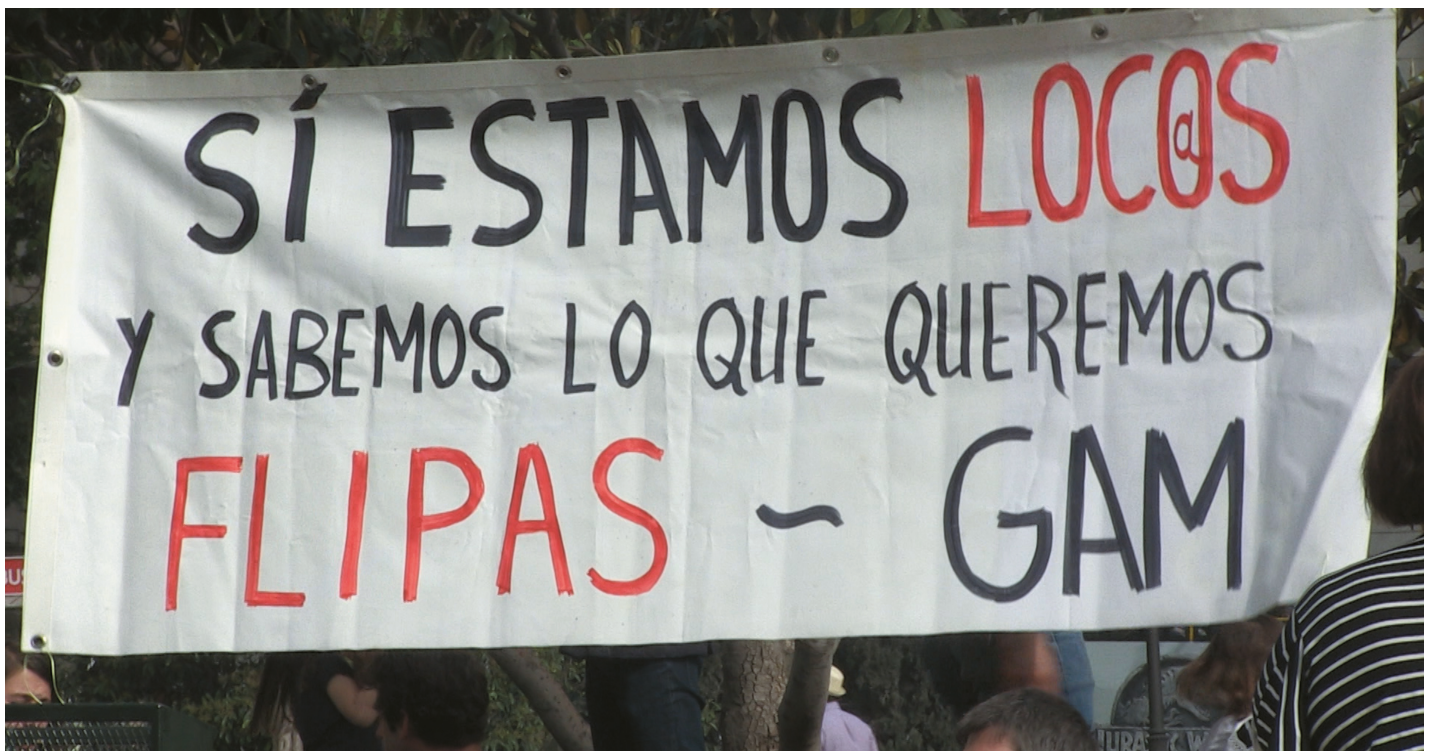

Fig. 3. María Ruido. Estado de Malestar (malestar_exhuberancia_anomalía). 2018. Secuencia del vídeo ensayo. Imagen cortesía de la artista.

terapia política (political therapy) para desvincular los temas tratados de dificultades particulares, individuales. Estas reivindicaciones también pueden relacionarse con las corrientes antipsiquiátricas de los años setenta que alertaron sobre la sobremedicación y la alienación de los ciudadanos. Aquí cabe apuntar que Rendueles fue pionero en aplicar las tesis de la antipsiquiatría en España, en los años setenta, y sostiene en una entrevista realizada por Fidel Moreno:

Bertolt Brecht decía que solo al que le queman los pies en la cabaña se decide a salir afuera sin reparar si llueve o truena. «Solo de los sin esperanza nos viene la esperanza»"; es el final de un libro de Marcuse que sirvió de programa a mi generación. En ambas citas quiero ver esas posibilidades de cambio. Politizar las tristezas escuchadas en los consultorios requiere perder la esperanza de mejorar con los fármacos o los consejos que en ellos se prescriben para descubrir la etiología del dolor. Confiar en los otros cercanos más que en un profesional lejano para que alivie mis duelos requiere tiempo de convivencia juntos para evitar el dilema del prisionero, que prescribe traicionar antes de que el otro me traicione. De esas desilusiones debe nacer el sentimiento de que las soluciones son de todos o de ninguno, como también repetía Brecht, y eso de nuevo requiere tiempo ${ }^{17}$.

Esta necesidad de repensar soluciones colectivas la plantean precisamente dos mujeres que forman parte de los grupos de apoyo mutuo del colectivo InsPiradas de Madrid, quienes vertebran - a partir de su conversación con la autora- las reflexiones esbozadas en el vídeo ensayo Estado de Malestar. María Ruido enfoca a Vivi Naharro y Marta Plaza [fig. 2] quienes comparten su proceso de empoderamiento, al plantear que el sufrimiento no sólo es producto de una biografía personal sino también de un contexto social determinado. Alertan sobre la necesidad de ser productivos y productivas en el marco de un realismo capitalista que homogeniza a las personas, recordando una de ellas que su padre le repetía "-No te signifiques". Precisamente, ese "no significarse" conecta directamente con la feminización de los síntomas y con las estructuras de dominación patriarcales que silencian a las mujeres todavía hoy en día. En contraposición a tales "mandatos" familiares y sociales, Vivi Naharro y Marta Plaza exponen cómo el Día del Orgullo Loco hace bandera del insulto ${ }^{18}$ [fig. 3]

17 Rendueles, 2001: 21.

18 La organización del día del Orgullo Loco sostiene: "se trata de reivindicar la locura. De reapropiarnos de una palabra usada de modo despectivo y dañino contra nuestro colectivo, para darle un sentido nuevo, libre de connotacio- 
y hablan de su elección de pertenecer al grupo de apoyo mutuo no mixto InsPiradas, compuesto sólo por mujeres, para evitar las jerarquías de género y para compartir las experiencias que muchas mujeres han vivido en relación a la opresión patriarcal. Otro tema determinante que cuestionan son las exigencias sociales que se interiorizan y la determinación de desobedecerlas, de recordar que no es un problema individual sino social.

María Ruido les pregunta por el germen de la politización de su malestar y citan la ponencia "Voces descalificadoras, contexto social y práctica de la desobediencia"19 de Fernando Alonso, del colectivo Entrevoces (España), como uno de los detonadores. Es necesario recordar, para valorar el impacto de Alonso en Vivi Naharro y Marta Plaza, que éste habla en primera persona cuando explica que empezó a escuchar voces a los 19 años y relata cómo el colectivo Hearing Voices, en el marco de un congreso, le ofreció la oportunidad de reflexionar sobre la conexión de la biografía con el contexto, cuestionando el círculo perverso de la sobremedicalización que tapa los síntomas anclando a los sujetos a las espirales de sufrimiento. Alonso denuncia cómo desde la psiquiatría no se plantea intervenir en lo social cuando las consultas aumentan como consecuencia directa de un contexto de recortes sociales, reformas laborales, desahucios, opresión de género, desigualdades y precariedad, que afectan directamente a la vida psíquica de las personas ${ }^{20}$. Apela a la responsabilidad ética, a la necesidad de relacionar las patologías de la vida cotidiana con un diagnóstico social y a pensar cómo transformarlo, cómo revertir la situación ofreciendo una resistencia activa. El objetivo es ir más allá de los discursos de superación personal y plantearlo en términos colectivos, desde el activismo, insistiendo en que no somos personas aisladas y escindidas de la sociedad. Propone trazar límites y denunciar los conflictos de intereses de las grandes multinacionales farmacéuticas y del poder terapéutico. Asimismo, plantea recuperar la autonomía a partir de la generalización de "Espacios de seguridad", grupos de apoyo mutuo donde se comparta y sociabilice el conocimiento y se bosquejen estrategias de manera activa, autogestionada.

Vivi Naharro y Marta Plaza se sintieron directamente interpeladas en la determinación de poner las experiencias en común, tomar la palabra y pensar de manera colectiva cómo afrontar un sistema que oprime, desobedeciendo unos imperativos sociales que pautan las exigencias internas. Justamente, la voz en off del curador Alfredo Aracil ${ }^{21}$ — acompañada por secuencias de un concurso hípico - alerta sobre la cotidianidad del malestar que aparece en distintas situaciones: "una persona haciendo la declaración de la renta, malestar es una persona cobrando una mierda a final de mes, mandando currículums por internet, buscando pisos en idealista; ese es el malestar". En clara relación con lo expuesto una de las personas que leyó el manifiesto el Día del Orgullo Loco, en la Plaza de España de Madrid, denunció la invisibilidad de las personas con problemas de salud mental: "Consideramos que el actual modelo, económico, político y social basado en el aislamiento, la individualidad, la homogenización está generando graves crisis mentales en nuestra sociedad". La lectura del manifiesto sigue exigiendo la participación directa y real de los afectados en todas las decisiones políticas y sociales sobre dicho tema, fomentando la presencia de expertos en primera persona en las consultas, centros, y solicitando una protección especial para la infancia y adolescencia en relación a la sobremedicación.

En dicha manifestación se aglutinaron diversos colectivos como las InsPiradas, el grupo Vallekas de la Plataforma de Afectados por la Hipoteca (PAH) que vincula directamente la depresión y la ansiedad con los procesos de desahucio, y el colectivo LGTBI que denuncia que para

\footnotetext{
nes negativas. De hacer del insulto bandera. De combatir el estigma con su propia medicina". En: <https://consaludmental.org/eventos/dia-orgullo-loco-35688/> [5 de enero de 2019].

19 Alonso, 2015. En: <https://vimeo.com/158766713> [10 de febrero de 2019].

20 Aquí es preciso citar el trabajo de investigación de Iván Mata y Alberto Ortiz quienes advierten sobre el alto nivel de psiquiatrización y psicologización del malestar social en las sociedades capitalistas que se concreta en una amplia oferta asistencial, "conductista", individual, que privatiza y despolitiza la zozobra existencial. Mata Ruiz/ Ortiz Lobo, 2007: 45-46.

${ }^{21}$ Alfredo Aracil es curador de la exposición Apuntes para una psiquiatría destructiva, en la Sala de Arte Joven de Madrid, 2017.
} 


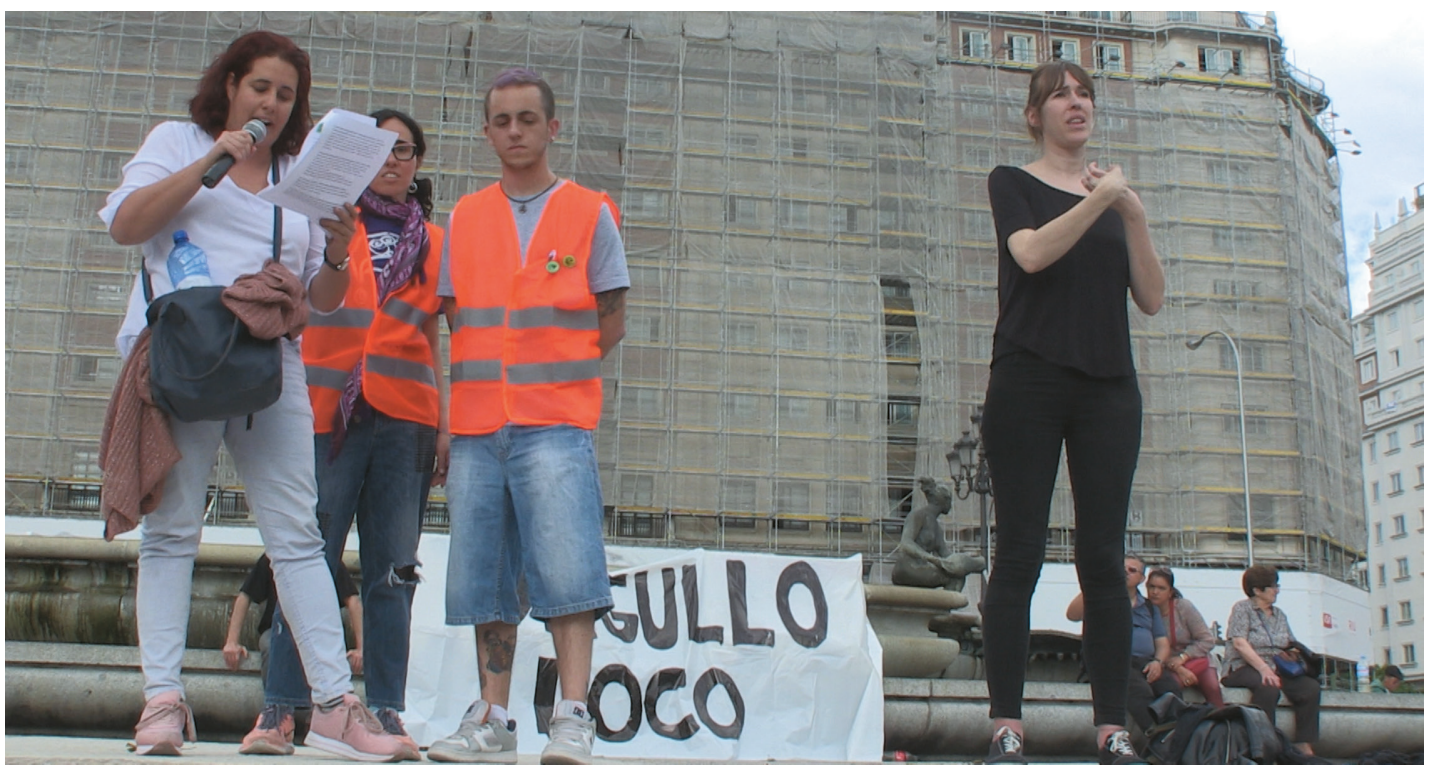

Fig. 4. María Ruido. Estado de Malestar (malestar exhuberancia anomalía). 2018. Secuencia del vídeo ensayo. Imagen cortesía de la artista.

solicitar un cambio de nombre en el DNI se necesitan informes psiquiátricos que avalen la disconformidad con una identidad de género que no concuerda con el sexo biológico. En dicho encuentro podía verse una pancarta en la que se proclamaba "La Libertad es Terapéutica", que sintetizaba varias de las demandas expuestas, y la manifestación festiva y reivindicativa - con conciertos, batucadas y una actuación del Teatro de los invisibles ${ }^{22}$ - devino un mecanismo para visibilizar dicha realidad, conectando lo personal con lo político [fig. 4].

El vídeo ensayo recoge la necesidad de generar un pensamiento crítico y esta voluntad conecta con el pensamiento de distintos autores como Mark Fisher, Franco Berardi y Santiago López Petit. La filosofía de tales pensadores, que aparece articulada mediante el hilo de su propia voz o bien a partir de fragmentos de textos leídos por un niño y una niña, se entreteje con los testimonios y las reflexiones de Vivi Naharro y Marta Plaza, del psiquiatra Guillermo Rendueles y del curador Alfredo Aracil. Justamente, varios textos de Mark Fisher alertan sobre la privatización de la enfermedad en los últimos treinta años en las sociedades capitalistas, en un contexto postdisciplinario que desvincula las "enfermedades del capitalismo neoliberal" de su fundamentación social, tratando a los sujetos de manera aislada, despolitizando así dichos malestares. Dicho pensador advierte:

No es sorprendente que sientan ansiedad, depresión o falta de esperanza quienes viven en estas condiciones, con horas de trabajo y términos de pago que pueden variar de modo infinito, en condiciones de empleo terriblemente tenues. Sin embargo, puede llamar la atención a primera vista, que se logre persuadir a tantos trabajadores de que acepten este deterioro en las condiciones de trabajo como «naturales», y que se ponga el foco en su interioridad (ya sea en las características de su química cerebral o en la de su historia personal) para encontrar las fuentes del estrés que puedan sentir. [...] El término que he utilizado para describir este campo de batalla ideológico es el «realismo capitalista», y la privatización del estrés ha desempeñado un rol central en su emergencia ${ }^{23}$.

22 Flipas GAM es un colectivo madrileño de activismo sociopolítico para construir espacios y herramientas para afrontar el sufrimiento psíquico desde lo colectivo. Los grupos de apoyo mutuo (GAM) en salud mental son determinantes para empoderarse y combatir el malestar a partir del activismo y diferentes lenguajes artísticos.

${ }^{23}$ Fisher, 2017: 126. Dicho autor reflexiona sobre el resentimiento y piensa cómo convertir la desafección privatizada en ira politizada: "Resentimiento versus desprecio y condescendencia. Resentimiento y descontento: el comienzo de la resistencia contra la positividad obligatoria del realismo capitalista". Fisher, 2018: 277. 


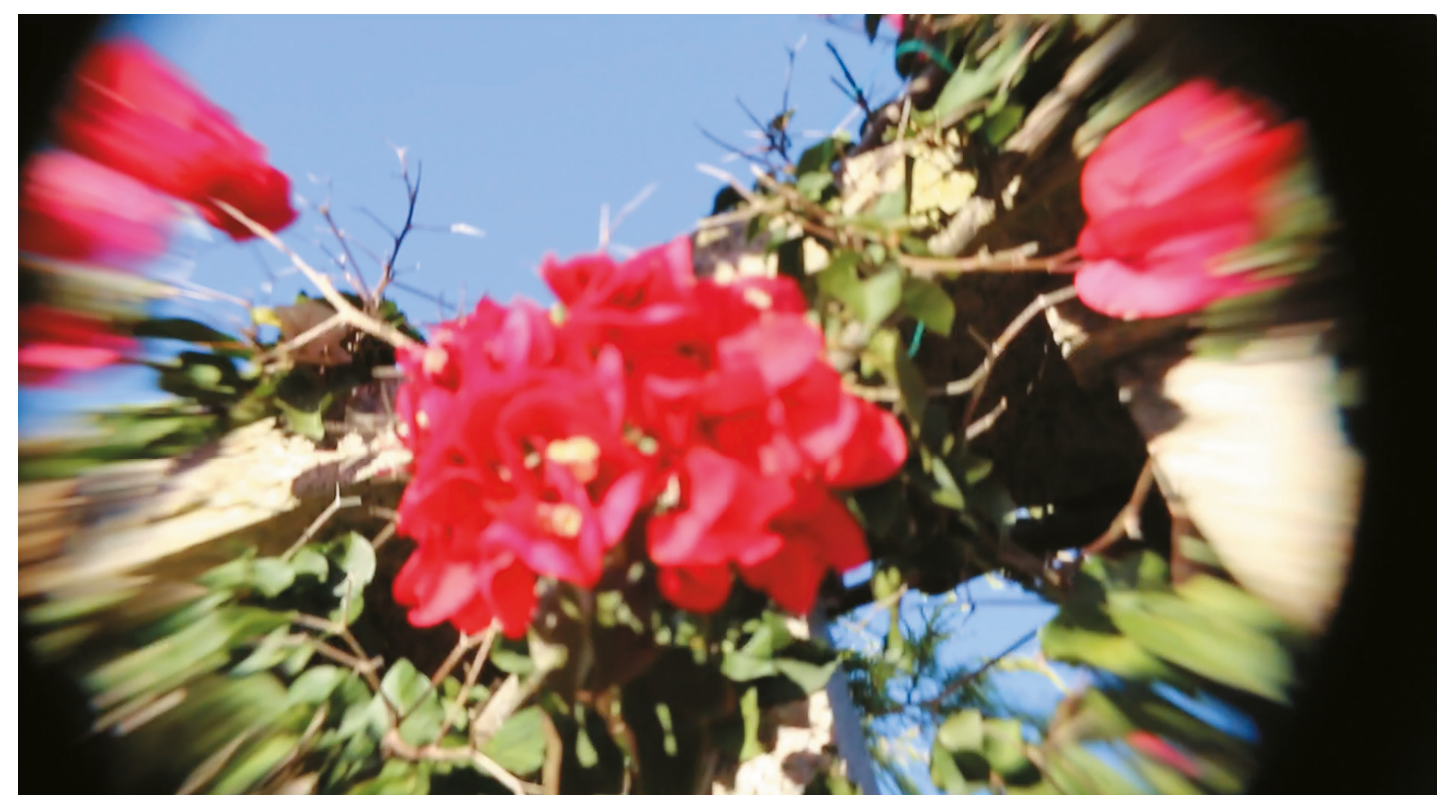

Fig. 5. María Ruido. Estado de Malestar (malestar_exhuberancia_anomalía). 2018. Secuencia del vídeo ensayo. Imagen cortesía de la artista.

Fisher explicita cómo el capital enferma al trabajador y luego las compañías farmacológicas internacionales "le venden drogas" para que se sienta mejor, individualizando, interiorizando el estrés. Otra cuestión es la propagación de manuales de autoayuda, el emprendedorismo psíquico del "voluntarismo mágico", dejando de lado las causas sociales y políticas que provocan los episodios de crisis $^{24}$.

Dentro de los mismos parámetros, mientras el zoom de la cámara se aproxima a matorrales, matojos, flores y buganvillas, la voz de Santiago López Petit explica cómo las personas que - como él - padecen fatiga crónica son de alguna manera "víctimas de esta sociedad que tritura, machaca, mata incluso" aunque puntualiza "mantenernos en pie, aunque sea de esta manera loca, impugna el funcionamiento de la misma sociedad" [fig. 5]. López Petit señala que el poder terapéutico mantiene a los afectados con este mínimo de vida para ir funcionando y reflexiona sobre las llamadas enfermedades del vacío vinculadas al trabajo, a la explotación, apuntando que el $70 \%$ de las bajas laborales de larga duración son de trabajadores con trastornos mentales. Cabe recordar que la sociedad espolea al trabajador a que sea autónomo, a que emprenda, y —en tal contexto - el poder deviene un "poder terapéutico" que impone la persistencia del "ser precario" para desactivar políticamente el malestar sistémico ${ }^{25}$. En tal escenario López Petit expone -en varias de sus obras - cómo, hoy en día, para politizar la existencia tenemos que desokupar el "ser precario" que nos impone el sistema capitalista ${ }^{26}$. La enfermedad puede convertirse en un arma, como sostenían el Colectivo Socialista de Pacientes (1972) y el colectivo InsPiradas, y

${ }^{24}$ Fisher, 2017: 135-137.

${ }^{25}$ López Petit expone: "En la época global, el malestar social es la enfermedad que acusa a esta sociedad de ser opresiva, huera, descarnada, injusta. Es un estar-mal que se manifiesta en una multitud de enfermedades indefinidas y generalizadas [...]. De la misma manera que el ser, el malestar social se dice de muchas maneras, aunque todas ellas tienen la misma referencia esencial: querer vivir y no poder. $\mathrm{Y}$ ese querer vivir que no puede actúa tanto hacia adentro (interiorización del vacío, sistema inmunitario estallado...) como hacia fuera (descoloca, frena...). ¿Cómo llamar a la enfermedad de la normalidad? El nombre más adecuado es seguramente el de fatiga". López Petit, 2014: 71.

${ }^{26}$ En relación a estas ideas López Petit explica: "El ser precario tiene que persistir porque comporta un tipo de vulnerabilidad que produce el máximo de beneficios para el capital. Desde esta perspectiva, el poder terapéutico actua- 


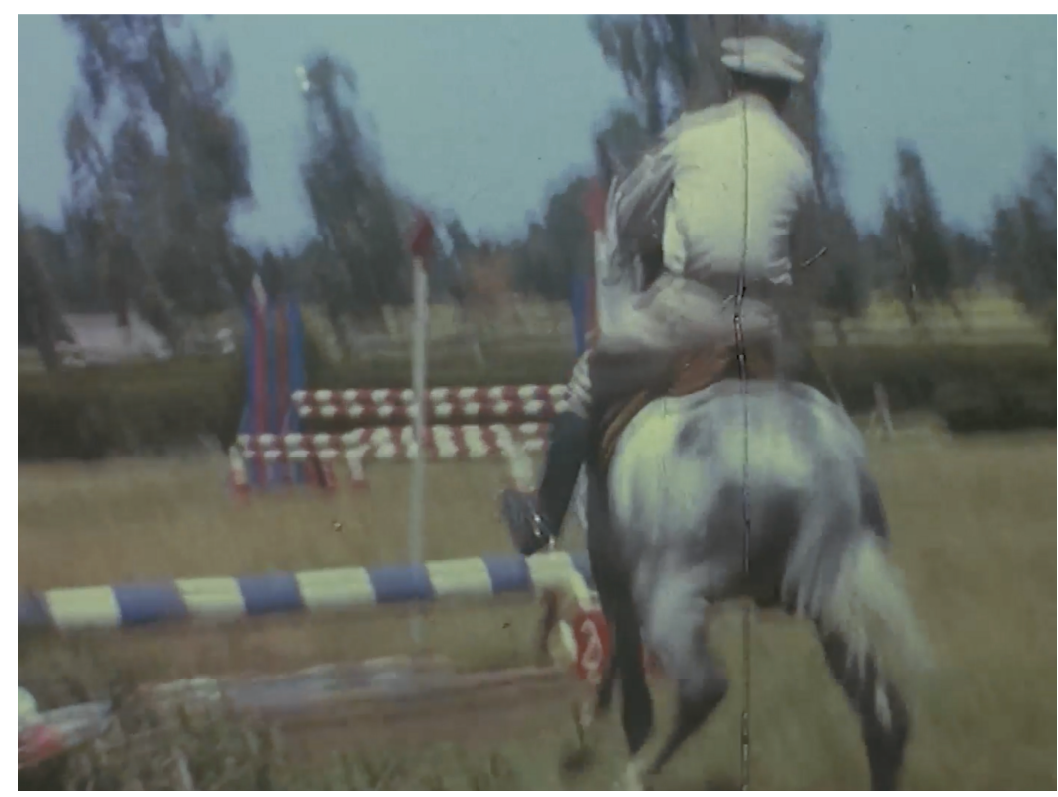

Fig. 6. María Ruido. Estado de Malestar (malestar exhuberancia anomalía). 2018. Secuencia del vídeo ensayo. Imagen cortesía de la artista.

López Petit - en la conversación recogida en el video ensayo - remarca el objetivo de politizar la existencia y el estatuto filosófico político de la anomalía:

Porque la anomalía no es una disfuncionalidad, no es un mal funcionamiento, que se repara, tampoco la anomalía es un déficit que un día se completará, es como un concepto más dialéctico. Esta ambivalencia de la anomalía es justamente que está girando, está pivotando entre lo que sería el centro de dolor y la fuerza de dolor y en este punto es donde se juega quedarte encerrado en el centro de dolor y buscar en la religión una explicación o hacerte con la fuerza de dolor y entonces sentir una cierta extraña alegría.

El corpus de pensamiento que se articula en Estado de malestar se apuntala también con un recorrido de fragmentos de imágenes, procedentes del Archivo Prelinger, del archivo de la familia Bensai (Casablanca), de La porte (1980) de Essedik Jeddi y Moncef Letaief en colaboración con los y las usuarias del Hospital Razi de Túnez, y de las secuencias de las películas Notre musique (2001) de Jean Luc Godard, Ombres chinoises (1982) de Raoul Ruiz y Armonías de Werckmeister (2000) de Béla Tarr. Con estos retazos fílmicos, simbólicamente escogidos, se ilustran los discursos expuestos y ciertas secuencias cinematográficas - como las escenas de un grupo destrozando el hospital de Armonías de Werckmeister de Tarr- sirven de transición entre las distintas vivencias y reflexiones que componen el ensayo visual. Con estas imágenes María Ruido esboza la alienación, la violencia, el miedo, el caos, la sinrazón, los fantasmas, las sombras y la fragilidad de la existencia. La artista trabaja con asociaciones de distintos tipos de imágenes - entrevistas, archivos y películas que manipula, en el proceso de edición, e imágenes creadas - para que dialoguen con la narración discursiva creando, a su vez, nuevos significados que interpelan al espectador. La curadora Cèlia de Diego reflexiona sobre el poder creador del montaje de María Ruido: "Las producciones de María Ruido se convierten en una experiencia de complejidad conceptual y formal en las que confluyen el apropiacionismo y el re-montaje de metraje encontrado, un vasto catálogo de citas de filósofos y teóricos" ${ }^{27}$.

rá con el fin de adaptar el querer vivir a la realidad y, a la vez, para inutilizar políticamente todo tipo de malestar social que se pueda producir". López Petit, 2007: 22-23.

27 Del Diego, 2015: 7. 
La artista trabaja con imágenes creadas especialmente para Estado de malestar e imágenes que aparecen en su obra L'oeil impératif $(2015)^{28}$, en concreto escenas de una madre y sus hijos pequeños jugando a la pelota, en bañador, procedentes del Archivo privado de la familia Bensai (Casablanca, 1957-1962), y retazos de una filmación de una competición hípica. Este concurso hípico, extraído de imágenes de archivo, es manipulado por la artista en el proceso de montaje, distorsionando las secuencias y dislocándolas para evocar lo que hay detrás de un mundo hipercompetitivo, donde prima el "ser para el otro", el simulacro. Las secuencias de archivo que muestran momentos de ocio familiar y actos sociales se contraponen con otras imágenes que nos remiten a un mundo fabril, de explotación laboral, de sombras, opresión, violencia, angustia y revuelta, procedentes de fragmentos de películas de Godard, Ruiz y Tarr. La música electrónica es esencial porque acompaña a tales imágenes despertando un estado de tensión, de alerta. Respecto a la selección de las escenas la voz en off de la artista explica - mientras puede verse una carrera de caballos [fig. 6] - que quiere distanciarse de las representaciones tradicionales de la locura, como la propuesta fotográfica de Raymond Depardon en el Hospital Psiquiátrico de Trieste (1979), para que no nos acerquemos a ésta como algo ajeno, que atañe a "Otros", sino que busca imágenes en las que nos reconozcamos.

Es importante recalcar que la artista decide alejarse de las representaciones que desde la historia del arte se han realizado de los trastornos psíquicos, recordando aquí La nave de los locos (1490-1500) de Hieronymus Bosco — inspirado en el poema satírico de Sebastian Brant (1494) _ como uno de los ejemplos paradigmáticos de una mirada que relaciona al enfermo con los vicios y los pecados capitales. Ruido también se aparta de la fascinación hacia los trabajos artísticos de pacientes psiquiátricos coleccionados por el psiquiatra e historiador del arte Hans Prinzhorn, quien animaba a los pacientes a desarrollar su creatividad para analizar después sus trabajos artísticos desde el prisma de la psiquiatría y la psicología. Tal colección de obras de pacientes psiquiátricos influyó en el artista Jean Dubuffet, quien defendió la pureza y la espontaneidad del arte hecho por enfermos psíquicos, autodidactas, inadaptados y personas fuera del sistema, acuñando el término l'Art brut, en 1945, en el contexto quebrado de la Segunda Guerra Mundial. Prinzhorn, Dubuffet y los Surrealistas se aproximaron a las producciones hechas por "locos" como objeto de estudio y de inspiración, desde la reapropiación y la estetización, sosteniendo todavía una mirada al Otro. Aquí es pertinente mencionar a la historiadora Kaira M. Cabañas, quien especifica en su investigación que utiliza los términos paciente-artista (patient-artist) y producción creativa de los pacientes (patient's creative production) en contraposición a expresiones como art brut: "I use asylum art, art of the insane, art of the alienated, psychopathological art, outsider art, and art brut when tracking how their creative expressions have been historically categorized within psychiatric practices as well as art history"29. María Ruido también evita toda categorización puesto que no se puede obviar que, a lo largo de la historia del arte, la "locura" ha sido representada, en numerosas ocasiones, incidiendo en señalar la Alteridad. Con todo, este vídeo ensayo no recoge la producción artística de pacientes ni los representa puesto que la artista, quien ha vivido un episodio de quiebra, aglutina tanto su propia experiencia como las voces de personas afectadas - profesionales y pacientes - para autorepresentarse ${ }^{30}$, huyendo así de la construcción de clichés y estereotipos. La propuesta de María Ruido ni estetiza ni se sitúa

28 En el video ensayo L'oil impératif / El ojo imperativo / The imperative eye (2015) María Ruido parte de textos reescritos de Frantz Fanon y Aimé Césaire para pensar sobre el colonialismo, la colonialidad actual en el marco del capitalismo y las soberanías visuales.

29 "Utilizo el arte del asilo, el arte de los locos, el arte de los alienados, el arte psicopatológico, el arte marginal y el arte bruto cuando observo cómo sus expresiones creativas se han clasificado históricamente dentro de las prácticas psiquiátricas y de la historia del arte”. Traducción de la autora. Cabañas, 2018: 11.

${ }^{30}$ En la misma dirección es pertinente mencionar la obra Portrait, Oblique (2005) de Ingrid Wildi, en la cual la artista filma a su hermano Hans Rudolf Wildi — interno en un Centro de Salud Mental— mientras que éste le expone cómo "le hacen sentir" por el hecho de estar deprimido. Hans Rudolf Wildi explica que le obligan a vivir una supuesta "normalidad" a partir de la ingestión de ansiolíticos y antidepresivos para no desencajar en un contexto homogéneo, apuntando que los psicofármacos conllevan una pérdida de identidad, en una sociedad que penaliza el ser diferente, al pobre y al enfermo. 
en las coordenadas del arteterapia que se centra en disolver una angustia individual, puesto que el objetivo de la artista es situar, recontextualizar y politizar el malestar.

\section{El hoy es malo pero el mañana es mío}

La filósofa Marina Garcés, miembro del colectivo Espai en Blanc ${ }^{31}$ conjuntamente con Santiago López Petit entre otras personas, en varios de sus escritos reflexiona sobre la necesidad de salir del rol de víctimas o espectadores - impotentes o indiferentes - a partir de la experiencia de dejarse afectar, de "ser afectado". Garcés recuerda la experiencia del atentado del 11 de marzo de 2004, en Madrid, y cómo las personas que sobrevivieron decidieron denominarse "afectados" en lugar de víctimas, dejando de lado un rol pasivo y potenciando una experiencia común que trascendía la gestión individualizada del malestar. Del mismo modo, dicha pensadora también recuerda las distintas acepciones de la palabra vulnerabilidad:

Por un lado, la vulnerabilidad señala las grietas de nuestra incompetencia o discapacidad emocional. Es lo que una nueva forma de poder, que podríamos llamar el «poder terapéutico», cultiva en nosotros, en nuestra necesidad de mediación experta e institucional en todas las dimensiones de nuestra existencia y en la gestión de nuestra vida precaria y privatizada [...]. La vulnerabilidad no es sólo receptiva. Significa también nuestra capacidad de exposición. Ser vulnerable es ser capaz de exponerse. En otras palabras, de ser afectado. En este sentido, la vulnerabilidad no sería una incompetencia o discapacidad individual, sino una potencia necesariamente colectiva ${ }^{32}$.

Marina Garcés se pregunta qué podemos hacer, pues el pensamiento crítico no puede limitarse a enunciar o denunciar, sino que debe ser encarnado. En esta dirección, María Ruido, en Estado de malestar, parte de la primera persona para posicionarse en el nosotros, en la capacidad de dejarse tocar. Estas ideas pueden dialogar con la ética del cuidado (care ethics) de la psicóloga Carol Gilligan, quien expone en su obra In a different voice (1982) la necesidad de repensar los afectos y emociones examinando la responsabilidad y la empatía que se generan en situaciones de dependencia donde es necesario el cuidado. Dicha autora señala el papel de la mujer y la necesidad de escuchar otras voces ${ }^{33}$, voces diferentes que cuestionen el contexto patriarcal y neoliberal, potenciando un homo empathicus en lugar de un homo lupus ${ }^{34}$. El ensayo visual deviene un instrumento para conectar lo personal con lo político y en La memoria interior (2002), con la entrevista a sus padres como eje del vídeo ensayo, Maria Ruido teje su memoria familiar enlazándola con la historia de la migración española a Alemania, hilvanando así una genealogía personal y colectiva para visibilizar unas historias que escasamente aparecen en un discurso histórico unívoco ${ }^{35}$. Recupera la memoria de su familia, de sus vecinos, narrando un relato plural a partir de entrevistas e imágenes de archivo que exponen las experiencias, las renuncias y las dificultades vividas. La exposición de la vulnerabilidad, como se ha citado previamente, remarca la potencia de lo común, contextualizando el malestar en un entorno de desigualdades sociales, devolviéndolo a una dimensión política.

31 Espai en Blanc: http://espaienblanc.net/

32 Garcés, 2008.

33 Es necesario apuntar que María Ruido, en un texto escrito conjuntamente Carmen Navarrete y Fefa Vila (2005), interpela críticamente a la "historia oficial" para dar visibilidad a las mujeres, utilizando las fuentes orales como un proceso esencial de la reconstrucción de la memoria y la historia.

34 Gilligan, 2013: 65.

35 Este compromiso puede relacionarse con el proyecto Antikeres (2010-2011) de Nora Ancarola y Marga Ximénez que, al igual que María Ruido, articulan dicho trabajo en entrevistas que visibilizan lo que la sociedad omite. Antikeres, la tercera parte del proyecto artístico La trilogía de la privacidad, presenta 55 entrevistas filmadas a personas que hablan del cuidado y el lenguaje audiovisual es el instrumento para recoger y compartir tales procesos. AAVV: 2011. 
Sonia Kerfa ${ }^{36}$ reflexiona sobre el trabajo de María Ruido y su documental Lo que no puede ser visto debe ser mostrado $(2010)^{37}$, subrayando el papel del cine contestatario para mostrar otras historias ${ }^{38}$. En Lo que no puede ser visto debe ser mostrado (2010) María Ruido recoge la afirmación "El hoy es malo pero el mañana es mío"39, que marcó a los colectivos activistas, que puede relacionarse directamente con la concepción del vídeo ensayo Estado de Malestar en el que se amalgama la voz subjetiva de la artista con las voces de las personas que comparten - desde la confianza y la complicidad - sus vivencias en relación a las enfermedades de salud mental. Es importante recalcar que la artista no se convierte en portavoz de nadie sino que propone un espacio común para pensar colectivamente, distanciándose de este modo de la advertencia de Craig Owens sobre la indignidad de hablar por otros y el riesgo de estetizar los problemas de grupos sociales discriminados ${ }^{40}$. Es especialmente significativo el hecho de que el vídeo ensayo Estado de malestar concluya con una obra de La Rara Troupe ${ }^{41}$, un colectivo que se define como un grupo de trabajo en torno a la salud mental, surgido el año 2012 e integrado por personas con y sin diagnóstico, que utiliza la creación audiovisual desde la autorepresentación y la narración en primera persona para pensar sobre la salud mental ${ }^{42}$. María Ruido finaliza Estado de malestar con un fragmento de la obra audiovisual El cuerpo del delito (2017) de La Rara Troupe, que nos invitan a que "Seamos el virus de esta red de poder" y a que hagamos una comunidad de cuerpos enajenados. En dicha creación audiovisual aparecen unos significativos subtítulos que acompañan la coreografía: "nos clasifican, nos ordenan, somos pixeles de gráfico. Queremos volver a tener panal, sin geometrías ni reinas, sin cajas artificiales. Queremos tener rizomas de pensamientos entrelazados, nutridos de tierra fértil y abonos naturales, desprotegidas, imperfectas". Puede verse cómo la creación se transforma en un medio para trabajar en comunidad y dar visibilidad a diversas problemáticas vinculadas con la salud mental, a la vez que se canaliza la angustia, la incertidumbre y el miedo.

\section{Consideraciones finales}

El colectivo InsPiradas, en su manifiesto, denuncia la feminización de los síntomas de la salud mental y la sobremedicación de las mujeres para silenciarlas y mantener las estructuras misóginas que sustentan dicha opresión. Vivi Naharro y Marta Plaza encarnan sus reflexiones y, en el vídeo ensayo, la cámara las enfoca a ellas y a los participantes del Día del Orgullo Loco de Madrid y a los niños que leen fragmentos de textos de los pensadores previamente mencionados. Es significativo observar que las voces en off de la periodista, del psiquiatra Guillermo Rendue-

\footnotetext{
36 Sonia Kerfa es docente e investigadora de la Université Grenoble Alpes y, en Seminario Espectros de otros 68: Genealogías estéticas y activismo global. (Universidad de Barcelona Barcelona, 9-10 de enero de 2019), reflexionó sobre el trabajo de María Ruido en el debate: "Presentación y proyección de la película de Helena Lumbreras, Spagna 68 y Lo que no puede ser visto debe ser mostrado de María Ruido en conversación con Mariano Lisa, Sonia Kerfa (Université Grenoble Alpes) y Jaime Vindel (Universidad Complutense de Madrid).

37 Lo que no puede ser visto debe ser mostrado (2010) versa sobre la memoria de la Transición recuperando producciones del cine militante que ponen en tensión las imágenes oficiales que acompañan la memoria del franquismo.

38 Juan Goytisolo reflexionó sobre el fermento contestatario en la creación en el discurso que pronunció cuando recogió el premio Cervantes: "No se trata de poner la pluma al servicio de una causa, por justa que sea, sino de introducir el fermento contestatario de esta en el ámbito de la escritura". Goytisolo, 2014.

${ }^{39}$ El mismo lema aparece como título de la novela El hoy es malo pero el mañana es mío (2017), de Salvador Compán, que trata sobre las secuelas de la Guerra Civil y toma el título de un verso del poema "Una España Joven" (1914) de Antonio Machado.

40 Owens, 1992.

${ }^{41}$ La Rara Troupe. En: <https://raraweb.org/> [3 diciembre de 2018].

${ }^{42}$ La Rara Troupe se reúne semanalmente en el DEAC (Departamento de Educación y Acción Cultural) del MUSAC (Museo de Arte Contemporáneo de Castilla y León) intentando generar espacios compartidos, comunes, y desde el año 2016 el grupo se integra en el Laav_(Laboratorio de Antropología Audiovisual Experimental). En: $<$ https://www. laav.es/> [20 diciembre de 2018].
} 
les, del curador Alfredo Aracil, del filósofo Santiago López Petit y de la propia artista, acompañan a una serie de imágenes de archivo, fragmentos de películas e imágenes de un entorno natural desdibujado, desenfocado, que dialogan con las ideas presentadas. El corpus teórico del ensayo visual, aunque se concibe desde la propia experiencia, no muestra los rostros y las expresiones de los autores, sino que su presencia es substituida por imágenes metafóricas que ilustran el discurso que nos brindan.

María Ruido reflexiona sobre si estamos en disposición de repensar el sistema visual desde la pluralidad y las alteridades o si bien este sistema seguirá anclado con las oligarquías: “¿Conseguiremos, en fin, reescribir el concepto de soberanía o soberanías visuales y actualizarlo según las nuevas necesidades de una multitud profundamente heterogénea e inteligente colectivamente?" 43 . Aquí cabe recordar el papel del cine contestatario en su labor de encuadrar otros relatos que quedan fuera del campo visual de la sociedad. Asimismo hay que remarcar, como apunta María Ruido en un diálogo con el poeta Alfonso Levy, que la autora concibe la primera persona del singular en conexión con la primera persona del plural $\mathrm{y}$, dentro de tales parámetros, el yo deviene un catalizador de lo colectivo ${ }^{44}$.

María Ruido yuxtapone imágenes de archivo con imágenes de creación propia, hibridando el pensamiento, el lenguaje ensayístico y la poesía. La autora apuesta por el ensayo visual para posicionarse críticamente ante el poder terapéutico, proponiendo un recorrido desde la autorepresentación, evitando la estetización y los estereotipos que se construyen en la mirada al "Otro", enfocando los gérmenes que impulsan acciones de resistencia y transformaciones sociopolíticas. María Ruido se nutre de un entramado de voces que dialogan, salvando jerarquías entre "especialistas" y pacientes puesto que todos son afectados, coincidiendo todos en señalar el problema de descontextualizar y despolitizar la ansiedad y el desasosiego. A partir de distintas vivencias nos invita a pensar colectivamente y perfila un pensamiento situado, atravesado por las reivindicaciones feministas, la antipsiquiatría y diversos movimientos sociales como el $15 \mathrm{M}$, enmarcando el malestar en unas coordenadas sociales, históricas y políticas concretas. ¿Pueden las prácticas artísticas convertirse en un fermento para transformar la cotidianidad e impulsar posiciones críticas? A partir de la propuesta esbozada puede constatarse que la creación puede devenir un dispositivo para dar que pensar, para investigar, compartir, denunciar y para experimentar otros modos de hacer producidos desde la autogestión y el mundo de los afectos, entendiendo la creación como una posible vía para repensar nuevas tácticas con el fin de intervenir la cotidianidad. El ser afectado y dejarse afectar devienen esenciales, así como el cuidado y la empatía, recordando el potencial transformador de unos procesos creativos que generan espacios de encuentro con el objetivo común de politizar un malestar sistémico. En Estado de malestar se engarzan la experiencia vital y el pensamiento, la creación y el activismo, mostrando los vasos comunicantes entre lo individual y lo colectivo, interpelando al espectador a que tome la palabra y se posicione para activar un pensamiento crítico.

\section{Agradecimientos}

Deseo agradecer a la artista María Ruido el acceso al vídeo ensayo y la cortesía de facilitar las imágenes de las secuencias que ilustran el artículo.

\section{BIBLIOGRAFÍA}

AAVV (2011). Trilogia de la privadesa, Nora Ancarola \& Marga Ximénez. Barcelona: Mxespai.

43 Ruido, 2015: 13.

44 Diálogo entre Alfonso Levy y María Ruido, en Arts Santa Mònica, 24 de octubre de 2017, en el marco de la exposición colectiva Politizaciones del malestar en Ars Santa Mònica (2017). En: < http://polititzacionsdelmalestar.org/ activitats/alfonso-levy-maria-ruido/?lang=es $>$ [5 novembre de 2018]. 
Alonso, Fernando (2015): "Voces descalificadoras, contexto social y arte de la desobediencia". $7^{\circ}$ Congreso Mundial de Hearing Voices. Alcalá de Henares en Madrid, 6 y 7 de noviembre de 2015. En: $<$ https://vimeo.com/158766713> [10 de enero de 2019].

Berardi, Franco (Bifo) (2007): "La epidemia depresiva. Una lectura de Cho". En: Espai en Blanc. La Sociedad terapéutica. Materiales para la subversión de la vida. Barcelona: Editorial Bellaterra, pp. 177-187. En: <http://espaienblanc. net/?page_id=1725 > [20 diciembre de 2017].

Cabañas, Kaira M. (2018). Learning from madness: brazilian modernism and global contemporary art. Chicago: University of Chicago Press.

Colectivo Socialista de Pacientes (1972): "Convertir la enfermedad en un arma". En: SPK (Sozialistisches Patientenkollektiv - Colectivo socialista de pacientes). Con el prefacio de Jean-Paul Sartre al libro Hacer de la enfermedad un arma, abril, 1972. En Espai en Blanc. La Sociedad terapéutica. Materiales para la subversión de la vida. Barcelona: Editorial Bellaterra, pp. 199-203. En: <http://www.espaienblanc.net/?page_id=1741> [20 diciembre de 2017].

Del Diego, Cèlia (2005): "El colono hace la historia y sabe que la hace". Disparos, María Ruido, L'oeil impératif. Arts Santa Mònica. En: <https://issuu.com/artssantamonica/docs/af_publicacio_mariaruido_cast_ok>[8 juliol de 2019].

Fernández-Savater, Amador (2017): "Una fuerza vulnerable: el malestar como energía de transformación social". En: Ancarola, Nora/ Manonelles Moner, Laia/ Gasol, Daniel (eds): Politizaciones del malestar. Barcelona: Rayo verde: 35-55. En: <http://www.eldiario.es/interferencias/malestar-energia-transformacion_social_6_606199392.html> [5 noviembre de 2018].

Fisher, Marc (2017): Realismo capitalista ¿No hay alternativa? Buenos Aires: Caja Negra.

Fisher, Marc (2018): Los fantasmas de mi vida. Escritos sobre depresión, hauntología y futuros perdidos. Buenos Aires: Caja Negra.

Garcés, Marina. (2008): “QQué podemos? De la conciencia a la encarnación en el pensamiento crítico actual”. Eipcp european institute for progressive cultural policies. En: <http://eipcp.net/transversal/0808/garces/es $>$ [3 junio de 2019].

Gilligan, Carol. (2013). "La resistència a la injustícia: una ética feminista del cuidado". Cuadernos de la Fundació Víctor Grifols i Lucas 30. En: <http://www.secpal.com/\%5CDocumentos\%5CBlog\%5Ccuaderno30.pdf> [3 junio de 2018].

Goytisolo, Juan (2014): "Discurso completo de Juan Goytisolo en el Premio Cervantes 2014", Europapress, 2014. En: <http:// www.europapress.es/cultura/noticia-discurso-completo-juan-goytisolo-premio-cervantes-2014-20150423163314.html> [7 de junio de 2017].

Hanish, Carol (1969): "The personal is political”, 1969. Notes from the Second Year: Women's Liberation, en 1970. En: <www. carolhanisch.org/CHwritings/PIP.html > [5 de noviembre de 2017].

López Petit, Santiago (2007): "Politizaciones apolíticas". En: Espai en Blanc. La Sociedad terapéutica. Materiales para la subversión de la vida. Barcelona: Editorial Bellaterra, En: <http://www.espaienblanc.net/?page_id=1679> [6 de noviembre de 2018].

López Petit, Santiago (2014): Hijos de la noche. Barcelona: Editorial Bellaterra.

Manonelles Moner, Laia (2016): "La estética del cuidado; la creación como actitud y compromiso". Anales de Historia del Arte, vol. 26, pp. 253-272. En: <http://www.revistas.ucm.es/index.php/ANHA/article/viewFile/54056/49450>

Manonelles Moner, Laia (2017): "Politizaciones del malestar: fermentos contestatarios en la producción artística". En: Ancarola, Nora/ Manonelles Moner, Laia/ Gasol, Daniel (eds.): Politizaciones del malestar. Barcelona: Rayo verde.

Manonelles Moner, Laia (2018): “The Personal Is Political. Who Cares for Babies, The Sick and The Elderly?". En: Critical Cartography of Art and Visuality in the Global Age II, The Territories of the Contemporary. Cambridge: Cambridge Scholars Publishing, pp. 165-177.

Mata Ruiz, Iván/ Ortiz Lobo, Alberto (2007): "La colonización psiquiátrica de la vida". En: Archipiélago, cuadernos críticos de la cultura, vol. 76, Madrid, pp. 45-46.

Navarrete, Carmen/Ruido, María/ Vila, Fefa. (2005): “Trastornos para devenir: entre artes y políticas feministas y queer en el Estado español". Desacuerdos. Arteleku-Diputación Foral de Gipuzkoa, Museu d'Art Contemporani de Barcelona y UNIA En: <http://www.workandwords.net/uploads/files/Desacuerdos-2004.pdf $>$ [9 de febrero de 2019].

Peran, Martí (2015): Indisposició general. Assaig sobre la fatiga. Barcelona: Ajuntament de Barcelona. Fabra i Coates. Centre d'Art Contemporani.

Rendueles, Guillermo (2001): "El estado de malestar Una conversación con Guillermo Rendueles”. En: entrevista realizada por Fidel Moreno, con la participación de Borja Casani, para El Estado Mental, Núm. 1, Madrid. En: <https:// primeravocal.org/wp-content/uploads/2011/09/El_estado_de_malestar.pdf $>$ [5 de febrero de 2019].

Rendueles, Guillermo (2005): “Bossing, Moving: ¿Necesito psiquiatra o comité de empresa?”. En Norte de Salud Mental, Núm. 23, pp. 33-46.

Rendueles, Guillermo (2018): Suicidio(s). Madrid: Grupo 5.

Ruido, Maria, (2005): "L'oeil impératif/ El ojo imperativo/The imperative eye/L'ull imperatiu. Una invitación a pensar colectivamente sobre el colonialismo, las colonialidades y las soberanías visuales." Disparos, María Ruido, L'oeil impératif. Arts Santa Mònica. En: <https://issuu.com/artssantamonica/docs/af_publicacio_mariaruido_cast_ok> [8 juliol de 2019].

Ruido, María (2018): Estado de Malestar (malestar_exhuberancia_anomalía). Video ensayo expuesto en el Centro de Arte Arts Santa Mónica, Barcelona, del 13 de noviembre del 2018 al 13 de enero del 2019. Estado de Malestar (malestar_exhuberancia_anomalia) está producido por Xarxa de Centres d'Arts Visuals de Catalunya, Arts Santa Mònica-Departament de Cultura y LOOP Barcelona. 
Ruido, María (2017): "Diálogo entre Alfonso Levy y María Ruido". En el contexto de la exposición Polititzaciones del malestar en Arts Santa Mònica. En: <http://polititzacionsdelmalestar.org/activitats/alfonso-levy-maria-ruido/?lang=es $>$ [24 de octubre de 2017].

Owens, Craig (1992): “The Indignity of Speaking for Others: An Imaginary Interview”, Beyond Recognition. Representation, Power and Culture. Berkeley: University of California Press.

\section{Páginas Web}

Ruido, María. En: <http://www.workandwords.net/es> [20 de noviembre de 2018].

Orgullo Loco en Madrid. En: <https://consaludmental.org/eventos/dia-orgullo-loco-35688/> [20 de noviembre de 2018].

Flipas GAM. En: <https://flipartegam.wordpress.com/2018/01/16/flipas-gam-y-teatro-de-los-invisibles> [21 de diciembre de 2018].

La Rara Troupe. En: <https://raraweb.org/> [21 de diciembre de 2018].

Fecha de recepción: 28-III-2019

Fecha de aceptación: 05-VII-2019 